Article

\title{
Exploring Factors Associated with Patients Who Prefer Clinician-Sampling to HPV Self-Sampling: A Study Conducted in a Low-Resource Setting
}

\author{
Jessica Sormani ${ }^{1,2, *(\mathbb{D}, \text {, Bruno Kenfack }}{ }^{3,4}$, Ania Wisniak ${ }^{1}$, Alida Moukam Datchoua ${ }^{4}$, \\ Sophie Lemoupa Makajio ${ }^{1,5}$, Nicole C. Schmidt ${ }^{1,6}$, Pierre Vassilakos ${ }^{1,7}$ and Patrick Petignat ${ }^{1(\mathbb{D})}$ \\ 1 Gynaecology Division, Department of Paediatrics, Gynaecology and Obstetrics, University Hospitals of \\ Geneva, 1205 Geneva, Switzerland; ania.wisniak@hcuge.ch (A.W.); Sophie.Lemoupa@hcuge.ch (S.L.M.); \\ Nicole.schmidt@ksh-m.de (N.C.S.); pierrevassilakos@bluewin.ch (P.V.); Patrick.petignat@hcuge.ch (P.P.) \\ 2 School of Health Sciences, HES-SO University of Applied Sciences and Arts Western Switzerland, \\ 1227 Geneva, Switzerland \\ 3 Department of Obstetrics and Gynecology, Faculty of Medicine and Pharmaceutical Sciences, University of \\ Dschang, Dschang, Cameroon; brunokenfack@gmail.com \\ 4 Department of Gynaecology and Obstetrics, District Hospital of Dschang, Dschang, Cameroon; \\ moukamalida@gmail.com \\ 5 Faculty of Medicine, Institute of Global Health, University of Geneva, 1205 Geneva, Switzerland \\ 6 Faculty of Social Science, Catholic University of Applied Science, 55122 Mainz, Germany \\ 7 Geneva Foundation for Medical Education and Research, 1202 Geneva, Switzerland \\ * Correspondence: Jessica.di-vincenzo-sormani@hesge.ch
}

check for updates

Citation: Sormani, J.; Kenfack, B.; Wisniak, A.; Moukam Datchoua, A.; Lemoupa Makajio, S.; Schmidt, N.C.; Vassilakos, P.; Petignat, P. Exploring Factors Associated with Patients Who Prefer Clinician-Sampling to HPV Self-Sampling: A Study Conducted in a Low-Resource Setting. Int. J. Environ. Res. Public Health 2022, 19, 54. https://doi.org/10.3390/ ijerph19010054

Academic Editors: Marialaura Di Tella and Annunziata Romeo

Received: 12 November 2021 Accepted: 14 December 2021 Published: 22 December 2021

Publisher's Note: MDPI stays neutral with regard to jurisdictional claims in published maps and institutional affiliations.

Copyright: (c) 2021 by the authors Licensee MDPI, Basel, Switzerland. This article is an open access article distributed under the terms and conditions of the Creative Commons Attribution (CC BY) license (https:// creativecommons.org/licenses/by/ $4.0 /)$.

\begin{abstract}
Human papillomavirus (HPV) self-sampling (Self-HPV) is a promising strategy to improve cervical cancer screening coverage in low-income countries. However, issues associated with women who prefer conventional HPV clinical-sampling over HPV self-sampling may affect screening participation. To address this issue, our study assessed factors associated with women's preferences related to Self-HPV. This study was embedded in a large clinical trial recruiting women aged 30-49 years in a primary HPV-based study termed “3T-Approach" (for Test-Triage-Treatment), launched in 2018 at Dschang District Hospital, West Cameroon. Participants were invited to perform a Self-HPV. After the sampling and before receiving the results, participants completed a questionnaire about cervical cancer screening and their preferences and perceptions around Self-HPV. The median age of the 2201 participants was 40.6 (IQR 35-45) years. Most (1693 (76.9\%)) preferred HPV self-sampling or had no preference for either method, and $508(23.1 \%)$ preferred clinician-sampling. Factors associated with an increased likelihood of reporting a clinician-sampling preference were tertiary educational level (29.4\% CI: $25.6-33.6$ vs. $14.4 \%$ CI: $12.8-16.1)$ and being an employee with higher grade professional or managerial occupations (5.5\% CI: 3.8-7.9 vs. $2.7 \%$ CI: $2.0-3.5)$. The main reported reason for women preferring clinician-sampling was a lack of "self-expertise". Most women (>99\%) would agree to repeat HPV self-sampling and would recommend it to their relatives. HPV self-sampling in the cultural context of central Africa was well accepted by participants, but some participants would prefer to undergo clinician sampling. Health systems should support well-educated women to increase self-confidence in using HPV self-sampling.
\end{abstract}

Keywords: cervical cancer screening; HPV self-sampling; sub-Saharan Africa; preference

\section{Introduction}

Cervical cancer (CC) is the second most common cancer in Cameroon, with 2356 cases and 1787 deaths recorded in 2020 [1]. In sub-Saharan Africa, CC is the leading cause of cancer deaths in women, despite being a highly preventable disease [2]. The widespread understanding that almost all cervical cancer cases occur in women who were previously infected with human papillomavirus (HPV) has resulted in the development of HPV tests and primary HPV-based cervical cancer screening. Furthermore, HPV testing is performed 
on vaginal smear samples, which has the advantage of allowing collection by patients themselves (Self-HPV).

The World Health Organization (WHO) launched a global initiative in 2020 to eliminate cervical cancer and includes Self-HPV as a part of cervical cancer screening programs [3,4]. Systematic reviews support the finding that Self-HPV has similar sensitivity and specificity for detecting precancerous lesions to samples collected by a physician or nurse [5-7] and is considered a safe and acceptable screening method by users [8-12]. This approach reduces the discomfort and pain that can be associated with pelvic examination, is considered less invasive, allows women more autonomy and privacy, and might facilitate screening participation $[8,13,14]$. In the context of primary screening, a negative HPV result indicates a very low risk of developing CC within the next decade and a positive result can generally be safely managed by adequately trained health care providers [15].

Self-HPV provides an opportunity to increase screening coverage to $70 \%$ of eligible women as recommended by the WHO. However, there are still some uncertainties about the introduction of this method for all women engaged in routine screening campaigns. The main uncertainties reported by participants are the quality of the sample, lack of confidence that they will perform the test correctly, and the reliability of the results [16].

The above results were mostly focused only on the acceptability of self-sampling and were not contextualised to sub-Saharan African countries. For these reasons, our study aimed to evaluate sociodemographic factors associated with preference for conventional HPV clinician-sampling compared with Self-HPV, in order to propose effective screening strategies that are aligned with the WHO's recommendations. Currently the Cameroonian health system supports and follows the WHO's recommendations for cervical cancer screening. There is no effective national screening programme, but early opportunistic screening for cervical cancer by visual inspection with acetic acid and Lugol's iodine (VIA/VILI) is promoted and sporadic campaigns are organized [17].

\section{Materials and Methods}

\subsection{Setting and Study Design}

This study was embedded in the research project "Comprehensive Cervical Cancer Prevention and Better Women Health in Medium and Low-Resource Setting" launched in 2018 [15] by the University of Dschang, the Dschang District Hospital, the University of Yaoundé in Cameroon, and the University Hospital of Geneva, Switzerland [18].

\subsection{Study Procedures}

The research project was based on a "3T-Approach" (for "same-day test, triage and treatment"). After a one-hour health education group session, midwives individually provided detailed information about the study and collected written informed consent. A baseline survey including sociodemographic characteristics and medical history was also conducted. Self-HPV was performed by participants using flocked swabs (FLOQSwabs ${ }^{\circledR}$ Self Collection; Copan, CA, USA). Before performing the self-test, women received instructions and a support guide that provided detailed visual information about the procedure. They were instructed to wash their hands before the procedure; they then performed the test in a dedicated area within the screening room with a midwife available if needed. Instructions directed the women to hold the plastic head of the swab and insert the cotton tip into the vagina until it met resistance. Specimens were analysed by a point-of-care HPV test $\left(\right.$ GeneX pert $\left.^{\circledR}\right)$ using the Xpert HPV Assay (Cepheid, Sunnyvale, CA, USA), and results were available after one hour.

Women screened positive underwent visual inspection with acetic acid and Lugol's iodine (VIA/VILI) to detect whether pre-cancerous or cancerous lesions were visible. If the VIA/VILI result was positive, women were treated by thermal ablation or loop electrosurgical excision of the transformation zone (LEETZ) according to predefined eligibility criteria. Quality control was ensured by histological sampling (biopsies and endocervical curettage), which was considered the gold standard. 


\subsection{Acceptability of and Satisfaction with the HPV Self-Sampling Procedure}

After the self-sampling procedure and before receiving the result, women filled in a second survey in their native language. With the assistance of a midwife, the participants reported how they felt during the test, their satisfaction with the procedure, their levels of anxiety and discomfort, their willingness to take the test again, whether they would recommend the test, and where they thought the test should be conducted (at home vs. at a health care centre). Pain experienced during the self-sampling procedure was scored according to the Wong-Baker FACES ${ }^{\circledR}$ scale [19]. This validated scale consists of six different faces with a spectrum of pain intensity from 0 (no hurt) to 10 (hurts worst). We then formed two subgroups: medium pain (score $\leq 4$ ) and strong pain (score $>4$ ). A four-point Likerttype scale was used to evaluate the women's anxiety, discomfort, embarrassment, and level of confidence with scores ranging between 1 (not at all) to 4 (very). Study data were collected with paper Case Report Forms (p-CRF) by trained midwives and later transcribed into an electronic database (SecuTrial $\left.{ }^{\circledR}\right)$.

\subsection{Ethical Considerations}

The protocol obtained approval from the Cantonal Ethics Board of Geneva, Switzerland (Commission cantonale d'éthique de la recherche, $\mathrm{N}^{\circ}$ 2017-01110) and the National Ethics Committee for Research on Human Health, Cameroun (Comité national d'éthique de la recherche pour la santé humaine, CNERSH, $\mathrm{N}^{\circ}$ 2018/07/1083/CE/CNERSH/SP). The study protocol of the overarching $3 \mathrm{~T}$ Study was registered under ClinicalTrials.gov (number NCT03757299).

\subsection{Statistical Analysis}

Quantitative variables were expressed as means and standard deviations, and qualitative variables were expressed as percentages unless otherwise stated. Descriptive analyses were conducted to compare baseline sociodemographic and clinical characteristics according to the preference for clinician-sampled versus Self-HPV. Categorical variables were analysed by Pearson's chi-square or Fisher's test when appropriate. In addition, we used univariable and multivariable logistic regression models to identify sociodemographic factors associated with preference for HPV self-sampling. Education, employment status, and parity were used in the multivariable logistic regression model, and were selected based on their $p$-value in the univariable models. We used a two-sided level of significance of 0.05 . The analyses were conducted using the software package STATA ${ }^{\circledR} 16$ (Stata, College Station, TX, USA).

\section{Results}

\subsection{Epidemiological Characteristics}

A total of 2201 women were enrolled in the 3T-Approach between September 2018 and January 2021. Median age was 40.6 (IQR 35-45) years. Among participants, 406 $(18.4 \%)$ were HPV-positive, and $176(8 \%)$ had been previously screened (Table 1). Most (76.9\%) preferred HPV self-sampling or had no preference, and $508(23.1 \%)$ preferred clinician-sampling. Demographic characteristics of the participants are shown in Table 1 and stratified by procedure preference (self-sampled or neutral versus (vs.) cliniciansampled). There was a higher proportion of women with a tertiary education level in the clinician-sampling preference group (29.5\%) than in the Self-HPV preference or neutral group $(14.4 \%, p<0.001)$. Similarly, the proportion of women employed with higher grade professional or managerial occupations was higher in the clinician-sampling preference group (5.5\% vs. $2.6 \%, p=0.005)$. The Self-HPV preference group had a lower proportion of nulligravida than the clinician-sampling preference group $(1.9 \%$ vs. $3.0 \% ; p=0.001)$ and a higher proportion of women with more than five pregnancies $(56.6 \%$ vs. $47.4 \%$ $p<0.001)$. There was a higher proportion of women with more than five children in the self-sampling preference group than in the clinician-sampling preference group $35.8 \%$ 
vs. $26.1 \% ; p<0.001)$. No difference was found concerning previous HPV sampling by clinicians between the two groups.

Table 1. Baseline sociodemographic and clinical characteristics according to preference for cliniciansampled or self-sampled HPV test.

\begin{tabular}{|c|c|c|c|}
\hline Variable & $\begin{array}{l}\text { Preference for } \\
\text { Self-Sampled or } \\
\text { Neutral N (\%) }\end{array}$ & $\begin{array}{l}\text { Preference for } \\
\text { Clinician-Sampled N } \\
(\%)\end{array}$ & $p$-Value \\
\hline Participants recruited $(\mathrm{n}=2201)$ & $1693(76.9)$ & $508(23.1)$ & \\
\hline HPV testing results $(n=2201)$ & & & 0.179 \\
\hline Negative & 1391(82.2) & $404(79.5)$ & \\
\hline Positive & $302(17.8)$ & $104(20.5)$ & \\
\hline Age $(y)$, mean $\pm S D$ & $39.9(5.9)$ & $39.1(6.0)$ & 0.001 \\
\hline Marital status $(\mathrm{n}=2198)$ & & & 0.840 \\
\hline Single/divorced/widowed & $257(15.2)$ & $75(14.8)$ & \\
\hline Married/in relationship & $1435(84.8)$ & $431(85.2)$ & \\
\hline Education $(\mathrm{n}=2195)$ & & & $<0.001$ \\
\hline Unschooled/primary education & $541(32.0)$ & $106(21.0)$ & \\
\hline Secondary education & $905(53.6)$ & $251(49.6)$ & \\
\hline Tertiary education & $243(14.4)$ & $149(29.5)$ & \\
\hline Employment status $(\mathrm{n}=2198)$ & & & 0.006 \\
\hline Unpaid worker* & $422(25.0)$ & $126(24.9)$ & \\
\hline $\begin{array}{l}\text { Lower grade or intermediate } \\
\text { occupation } * * / \text { self-employed }\end{array}$ & $1224(72.4)$ & $352(69.6)$ & \\
\hline Higher grade occupation $* * *$ & $45(2.6)$ & $28(5.5)$ & \\
\hline Age at first delivery (y), mean $\pm S D$ & $20.7(5.1)$ & $21.4(6.2)$ & 0.006 \\
\hline Age at first intercourse $(y)$ mean $\pm S D$ & $17.9(2.7)$ & $18.0(3.0)$ & 0.354 \\
\hline Pregnancy $(n=2198)$ & & & 0.001 \\
\hline Nulligravida & $32(1.9)$ & $15(3)$ & \\
\hline $1-5$ & $702(41.5)$ & $251(49.6)$ & \\
\hline$>5$ & $958(56.6)$ & $240(47.4)$ & \\
\hline Parity $(n=2198)$ & & & $<0.001$ \\
\hline Nulliparous & $62(3.7)$ & $26(5.1)$ & \\
\hline $1-5$ & $1024(60.5)$ & $348(68.8)$ & \\
\hline$>5$ & $606(35.8)$ & $132(26.1)$ & \\
\hline Previous HPV screening $(\mathrm{n}=2197)$ & & & 0.405 \\
\hline No & $1560(92.3)$ & $461(91.1)$ & \\
\hline Yes & $131(7.7)$ & $45(8.9)$ & \\
\hline HIV status (self-reported) $(n=2156)$ & & & 0.535 \\
\hline Negative & 1601 (96.4) & 480 (94.5) & \\
\hline Positive & $60(3.6)$ & $15(5.5)$ & \\
\hline
\end{tabular}

Note: N, number; HPV, human papillomavirus; y, years; SD, standard deviation; HIV, Human Immunodeficiency virus, * Unpaid worker (ex: student, housewife), ** Employee with lower grade or intermediate occupation (ex: nurse, technician, and teacher), ${ }^{* * *}$ Employee with higher grade professional administrative or managerial occupations (ex: doctor, manager, school director).

\subsection{Acceptability of the HPV Self-Sampling Procedure by Sampling Preference}

Most women (98.3\% in self- and $96.9 \%$ in clinician-sampling; $p=0.053$ ) reported to be comfortable or very comfortable and confident or very confident $(98.9 \%$ vs. $99.4 \% ; p=0.341)$ during the self-sampling procedure. No significant differences were reported. The same observation was made among women who expressed no or low embarrassment $(99.3 \%$ vs. $98.6 \% ; p=0.107)$. However, among women who described feeling anxious (1.1\% vs. $3.5 \% ; p<0.001)$, we found that women who preferred clinician-sampling were significantly more anxious (Figure 1). The source of anxiety reported by most participants (86.0\% vs. $77.3 \%$ ) was fear of a positive result, followed by fear of the self-sampling procedure $(6.8 \%)$ in the clinician-sampled group, and fear of doing the self-test for the first time $(4.3 \%)$ in the self-test preference group. 


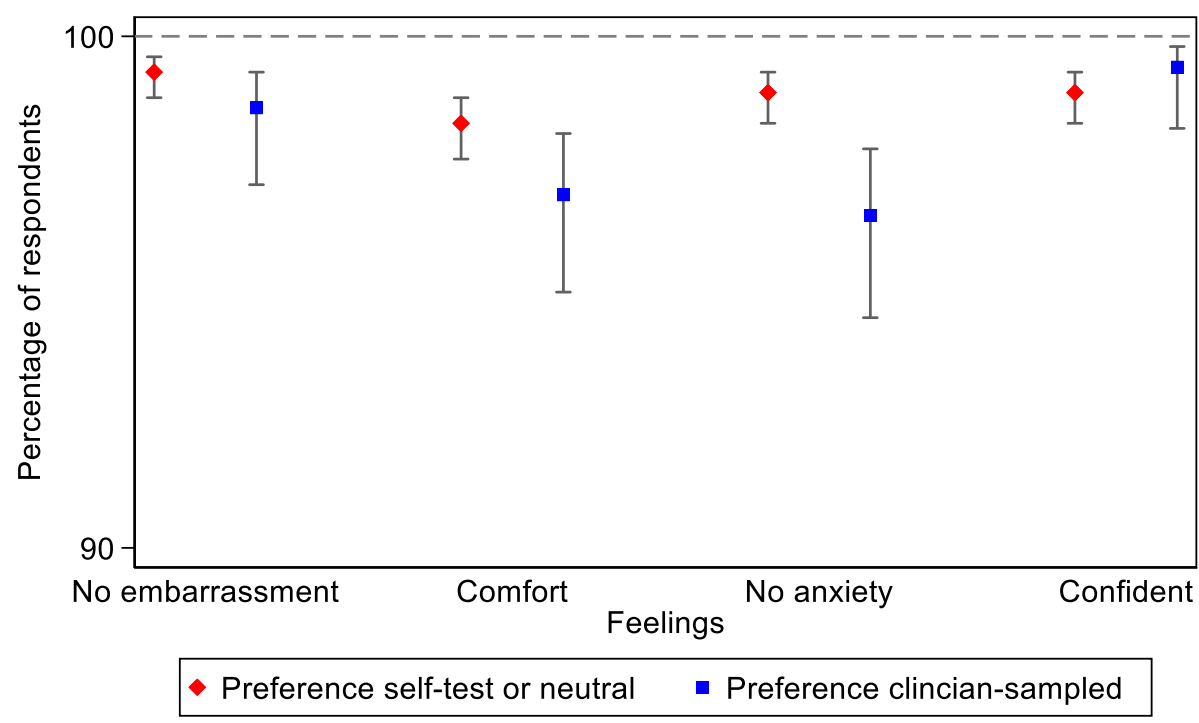

Figure 1. Comparison of women's experiences with Self-HPV (preference for self-test or neutral vs. clinician-sampled).

Few participants reported difficulties in performing the Self-HPV (1.2\% vs. $1.6 \%$; $p=0.488$, in the self-sampled or neutral and clinician-sampled preference groups, respectively). Fewer than $0.05 \%(1 / 2201)$ women reported pain (score $>4 / 10)$ during Self-HPV across the two groups. Most women in both preference groups were willing to repeat the self-test as a screening test $(99.8 \%$ vs. $99.2 \% ; p=0.035)$, and they agreed to perform it at home $(98.4 \%$ vs. $94.9 \% ; p<0.001)$. Only one woman in the self-sampled preference group and one in the clinician-sampled preference group reported that they would not recommend the procedure to their relatives. (Table 2).

Table 2. Comparison of feelings about HPV self-sampling between preference groups.

\begin{tabular}{llll}
\hline Feelings about Self-Sampling & $\begin{array}{l}\text { Preference for } \\
\text { Self-Sampled or } \\
\text { Neutral N (\%) }\end{array}$ & $\begin{array}{l}\text { Preference for } \\
\text { Clinician-Sampled } \\
\text { N (\%) }\end{array}$ & $p$-Value * \\
\hline Agree to repeat self-sampling & $1687(99.8)$ & $504(99.2)$ & 0.035 \\
Agree to perform self-sampling at home & $1666(98.4)$ & $481(94.9)$ & $<0.001$ \\
Difficult to perform self-sampling & $20(1.2)$ & $8(1.6)$ & 0.488 \\
Would recommend self-sampling & $1687(99.9)$ & $507(99.8)$ & 0.573 \\
Yes & $1(0.1)$ & $1(0.2)$ & \\
No & & \\
\hline
\end{tabular}

* Fisher's exact test used to account for low cell counts.

Univariate logistic regression showed an association between sociodemographic variables and preference for the clinician-sampled procedure. In particular, education level was significantly higher among women preferring clinician-sampling. Women having attended tertiary education were more than three times more likely to prefer clinician-sampling than women with primary education or no formal education (OR, 3.13; 95\% CI 2.34-4.19). Women having attended secondary education were 1.42 times more likely (95\% CI 1.10-1.82) to prefer clinician-sampling. These findings show a gradient in the association between level of education and preference for clinician-sampling. Compared with unpaid workers, women employed with higher grade professional or managerial occupations were more likely to prefer clinician-sampling (OR, 2.08; 95\% CI 1.25-3.48). However, no difference in preference was observed among women employed with lower grade or intermediate occupation or self-employed women compared with unpaid workers (OR, 0.96; 95\% CI $0.76-1.21)$. Parity was also associated with sampling preference, with women having more 
than five children being less likely to prefer clinician-sampling (OR, 0.52; 95\% CI 0.32-0.85) compared with nulliparous women.

In the multivariable logistic regression model, parity and employment status were no longer significantly associated with sampling preference. However, the gradient between level of education and preference for clinician-sampling remained, with women with a secondary or tertiary level of education showing a significant preference to undergo clinician-sampling (OR, 1.35; 95\% CI 1.05-1.75, and OR, 2.79; 95\% CI 2.03-3.82, respectively) (Table 3).

Table 3. Association of sociodemographic factors with preference for clinician-sampled.

\begin{tabular}{|c|c|c|c|c|}
\hline \multirow{3}{*}{ Sociodemographic Variables } & \multicolumn{4}{|c|}{ Clinician-Sampled } \\
\hline & \multicolumn{2}{|l|}{ Unadjusted } & \multicolumn{2}{|l|}{ Adjusted } \\
\hline & $\mathrm{OR} *(95 \% \mathrm{IC})$ & $p$-Value & OR $(95 \%$ IC) & $p$-Value \\
\hline \multicolumn{5}{|l|}{ Education } \\
\hline Unschooled/primary education & Ref & & Ref & \\
\hline Secondary education & $1.42(1.10-1.82)$ & 0.007 & 1.35 (1.05-1.75) & 0.019 \\
\hline Tertiary education & $3.13(2.34-4.19)$ & $<0.001$ & $2.79(2.03-3.82)$ & $<0.001$ \\
\hline \multicolumn{5}{|l|}{ Employment status } \\
\hline Unpaid worker * & Ref & & Ref & \\
\hline $\begin{array}{l}\text { Lower grade or intermediate } \\
\text { occupation **/self-employed }\end{array}$ & $0.96(0.76-1.21)$ & 0.751 & $0.91(0.72-1.15)$ & 0.435 \\
\hline \multicolumn{5}{|l|}{ Parity } \\
\hline Nulliparous & Ref & & Ref & \\
\hline $1-5$ & $0.81(0.50-1.30)$ & 0.384 & $1.06(0.65-1.73)$ & 0.824 \\
\hline$>5$ & $0.52(0.32-0.85)$ & 0.010 & $0.84(0.50-1.43)$ & 0.523 \\
\hline \multicolumn{5}{|l|}{ Pregnancy } \\
\hline Nulligravida & Ref & & & \\
\hline $1-5$ & $0.76(0.41-1.43)$ & 0.400 & & \\
\hline$>5$ & $0.53(0.28-1.00)$ & 0.051 & & \\
\hline \multicolumn{5}{|l|}{ Marital status } \\
\hline Married/in relationship & Ref & & & \\
\hline Single/divorced/widowed & $0.97(0.74-1.28)$ & 0.840 & & \\
\hline
\end{tabular}

\subsection{Perceptions Regarding the Sampling Procedure}

Most reasons for preferring self-sampling over clinician-sampling were its ease of use $(75.2 \%)$ and the possibility for increased privacy $(16.3 \%)$. The top reasons women gave for preferring clinician-sampling over self-sampling were feeling comfortable because of the clinician's greater experience $(76.1 \%)$ and the higher reliability of the results $(19.5 \%)$. The possibility to undergo a complete gynaecological exam $(2.5 \%)$ was a less common reason reported by women, as was the belief that sampling is the role of caregivers $(0.8 \%)$ (Table 4$)$. Most participants preferred performing self-sampling in a medical centre (96.6\%) over home-based screening, because they were afraid of performing the self-test inappropriately $(36 \%)$ or contaminating it $(12 \%)$ if performed at home. 
Table 4. Reasons for preferring HPV self-sampling or clinician-sampling *.

\begin{tabular}{lll}
\hline Reasons for preferring self-sampling $(\mathrm{n}=479)$ & $\mathrm{N}$ & $(\%)$ \\
\hline Easy and rapid & 360 & 75.2 \\
Affords privacy & 78 & 16.3 \\
Autonomous & 11 & 2.3 \\
Fear of gynaecological examinations & 11 & 2.3 \\
Reliability of results & 7 & 1.5 \\
Self-confidence & 6 & 1.3 \\
New learning experience & 6 & 1.3 \\
\hline Reasons for preferring clinician-sampling $(\mathrm{n}=486)$ & & \\
\hline Expertise of clinician & 370 & 76.1 \\
Reliability of results & 95 & 19.5 \\
Possibility of inspecting the cervix & 12 & 2.5 \\
Caregiver's role & 4 & 0.8 \\
Difficulty of performing the test & 3 & 0.6 \\
Ease of procedure & 2 & 0.4 \\
\hline${ }^{*}$ Multiple responses allowed. & &
\end{tabular}

\section{Discussion}

HPV self-sampling may be an effective approach to cervical cancer screening programs, although there are still challenges affecting its implementation. Because low-resource settings are progressively introducing both HPV-based primary screening and Self-HPV sampling $[20,21]$, we sought to explore factors associated with women's preference for sampling performed by health care providers in this context. Our study was conducted in a population where most participants had never undergone screening before $(92.0 \%)$. Our findings show that most women consider Self-HPV easy to use (97.9\%), as previously reported in the literature [22]. More than $99.5 \%$ of the women reported that they would agree to do it again, and $97.6 \%$ would agree to perform it at home.

Some women (23.1\%) preferred sampling performed by clinicians, as was previously reported in other studies [8,23-25]. In Cameroon, an earlier study explored the perceptions and preferences regarding self- versus physician-sampling in a population of women living with HIV and observed that most preferred clinician-sampling [26]. This was found in another study conducted in Britain among Muslim women interviewed in the context of cervical cancer screening [24]. The reasons for preferring clinician-sampling in these studies were concerns about not doing the test correctly and the belief that health providers are more expert $(95.6 \%)$, which is consistent with our findings. In the literature, women also reported having a low level of self-confidence performing self-sampling properly and providing a good quality sample for analysis [8,16,27-29].

Sociodemographic factors associated with women's preferences show that well-educated women prefer clinician-sampling. Similar findings were reported in Malaysia, where women with a high education level presented a low level of confidence in self-testing [22]. In China, authors investigated the preference for self-testing for streptococcus B infection instead of clinician-sampling, and their findings showed a similar tendency, that women with the highest education level were more likely to prefer clinician-collection [30]. The finding that women with a higher education prefer clinician-sampling may be explained by their increased questioning of their ability to perform the test themselves adequately [22]. Being able to afford going to a hospital to seek care may also influence the preference to have a clinician conduct cervical cancer screening. However, in a different study on vaginal HPV self-sampling, the authors found no association between level of education and preference for procedure type [31]. Cultural beliefs may also influence patients' perception of the self-sampling approach and the idea that health care provider attendance is needed during the procedure [22,29,32]. Qualitative studies could be useful to further explore reasons for clinician- versus self-sampling preferences. 
Educational interventions were highlighted as an effective way to improve women's self-confidence and clarify misconceptions $[29,33]$. Instruction about the validity of the test and how to collect the sample should be simple and should account for the women's cultural and social characteristics [13]. Women who have never used tampons or do not feel comfortable about touching their genital areas perceive this practice as taboo and appear less confident about performing a self-testing procedure $[13,16]$. Allowing them to observe and manipulate a swab during the educational intervention is one way to reduce their worries [32]. The presence of a healthcare provider during Self-HPV has been reported by some authors to have a positive effect on women. Support is therefore a way of increasing women's confidence and comfort $[8,28]$, but the option to choose clinical-sampled could be a solution for women who are unwilling to undergo Self-HPV, as was proposed in Australia [34]. In our program, an hour of educational and counselling intervention provided to women before performing the Self-HPV probably allows sufficient time to respond to the women's specific fears. Health care providers need to fully understand the Self-HPV screening procedure and should be able to give culturally appropriate messages to participating women [8]. They also need to be prepared to answer any concerns that women may have regarding Self-HPV. This requires rigorous theoretical and practical training of health care providers.

Community health workers and peer-to-peer education also contribute to increasing women's awareness and confidence in Self-HPV by providing them with adequate information [32]. The Cameroonian health system already provides an important value to the community approach to health promotion in the population, as is also the case in other African countries [32]. Political endorsements and health system support are key in this screening process and in health care training [35]. Recommendations on screening and management strategies for cervical cancer elimination from previous research should be applied at a state level, as is the case in Uganda, Rwanda, and Kenya, where these recommendations have been introduced into national guidelines $[20,21,36]$.

The strength of this study lies in the large sample size of women recruited in realworld screening conditions. In addition to the Self-HPV acceptability analysis, we assessed women's preferences regarding the screening procedure. Identifying associations between sociodemographic characteristics and screening preference contributes to providing adapted instructions to women and improving their experiences, thus increasing screening coverage.

There are two main limitations to this study. First, for illiterate women or those who were not comfortable answering independently, the questionnaires were completed with the help of midwives. This could have influenced the women's answers if any women were not comfortable discussing their feelings about intimacy-related topics in the presence of midwives. Second, the women recruited in our study and who took part in our screening program come from a constrained health area and have a higher level of education on average than the general female population in Cameroon [37]. Therefore, our results may not be generalizable to all women in Cameroon.

\section{Conclusions}

Self-HPV is highly accepted by women and is an effective method of detecting precancerous lesions. Our findings support a self-sampling approach as primary screening method. However, implementation of a community-based Self-HPV approach needs to be appropriate to the local context. Health systems should assist participants with the screening process to increase self-confidence about the accuracy of self-sampling. Given that a minority of participants prefer clinician-based sampling, an approach where women can choose the sampling method should be considered.

Author Contributions: Conceptualization P.P., B.K., P.V. and J.S.; methodology, P.P., B.K., P.V. and J.S.; software, J.S., A.W. and S.L.M.; validation, P.P. and B.K.; formal analysis, P.P., J.S., A.W. and A.M.D.; investigation, A.M.D. and S.L.M.; data curation, J.S. and A.W.; writing-original draft preparation, J.S. and P.P.; writing-review and editing, J.S., P.P., A.W., P.V., B.K. and N.C.S.; supervision, P.P. and 
B.K.; project administration, P.P., B.K. and J.S.; funding acquisition, P.P., B.K., P.V., A.W. and J.S. All authors have read and agreed to the published version of the manuscript.

Funding: This research was funded by ESTHER Switzerland 17G1, Service for international solidarity (State of Geneva), the University Hospital of Geneva (HUG) (Geneva, Switzerland), the Private Foundation of HUG (Geneva, Switzerland), the Commission of Humanitarian Affairs (HUG) (Geneva, Switzerland), and the Groupement Romand de la Société Suisse de Gynécologie et Obstétrique (GRSSGO) (Geneva, Switzerland).

Institutional Review Board Statement: The study was conducted according to the guidelines of the Declaration of Helsinki, and approved by Cantonal Ethics Board of Geneva, Switzerland (Commission cantonale d'éthique de la recherche [CCER], No. 2017-01110) and the Cameroonian National Ethics Committee for Human Health Research (No. 2018/07/1083/CE/CNERSH/SP).

Informed Consent Statement: Informed consent was obtained from all subjects involved in the study.

Data Availability Statement: The datasets analysed during this study are available from the corresponding author upon request.

Acknowledgments: We thank Lucy McClellan, MIA, from Edanz (https:/ /www.edanz.com/ac, accessed on 3 November 2021) for editing a draft of this manuscript.

Conflicts of Interest: The authors declare no conflict of interest. The funders had no role in the design of the study; in the collection, analyses, or interpretation of data; in the writing of the manuscript; or in the decision to publish the results.

\section{References}

1. Global Cancer Observatory. Cervix Uteri Source: Globocan 2020. Available online: https://gco.iarc.fr/today/data/factsheets/ cancers / 23-Cervix-uteri-fact-sheet.pdf (accessed on 30 August 2021).

2. ICO/IARC. HPV Information Centre. Available online: https://hpvcentre.net/datastatistics.php (accessed on 5 May 2021).

3. World Health Organization. Global Strategy to Accelerate the Elimination of Cervical Cancer as a Public Health Problem. Available online: https:/ / www.who.int/publications-detail-redirect/9789240014107 (accessed on 30 August 2021).

4. World Health Organization. WHO Recommendations on Self-Care Interventions: Human Papillomavirus (HPV) Self-Sampling as Part of Cervical Cancer Screening. Available online: https: / / apps.who.int/iris/handle/10665/332333 (accessed on 5 July 2021).

5. Denny, L.; Hu, C.; Tsai, W.; Wright, T. Human papillomavirus-based cervical cancer prevention: Long-term results of a randomized screening trial. J. Natl. Cancer Inst. 2010, 102, 1557-1567. Available online: https:/ / pubmed.ncbi.nlm.nih.gov/20884893/ (accessed on 5 July 2021). [CrossRef] [PubMed]

6. Petignat, P.; Faltin, D.L.; Bruchim, I.; Tramèr, M.R.; Franco, E.L.; Coutlée, F. Are self-collected samples comparable to physiciancollected cervical specimens for human papillomavirus DNA testing? A systematic review and meta-analysis. Gynecol. Oncol. 2007, 105, 530-535. [CrossRef]

7. Arbyn, M.; Smith, S.B.; Temin, S.; Sultana, F.; Castle, P. Detecting cervical precancer and reaching underscreened women by using HPV testing on self samples: Updated meta-analyses. BMJ 2018, 363, k4823. Available online: https://www.bmj.com/content/ 363/bmj.k4823 (accessed on 5 July 2021). [CrossRef] [PubMed]

8. Nishimura, H.; Yeh, P.T.; Oguntade, H.; Kennedy, C.E.; Narasimhan, M. HPV self-sampling for cervical cancer screening: A systematic review of values and preferences. BMJ Glob. Health 2021, 6, 003743. [CrossRef]

9. Leinonen, M.K.; Schee, K.; Jonassen, C.M.; Lie, A.K.; Nystrand, C.F.; Rangberg, A.; Furre, I.E.; Johansson, M.J.; Tropé, A.; Sjøborg, K.D.; et al. Safety and acceptability of human papillomavirus testing of self-collected specimens: A methodologic study of the impact of collection devices and HPV assays on sensitivity for cervical cancer and high-grade lesions. J. Clin. Virol. 2018, 99-100, 22-30. [CrossRef] [PubMed]

10. Berner, A.; Hassel, S.; Tebeu, P.-M.; Untiet, S.; Kenge-Fosso, G.; Navarria, I.; Boulvain, M.; Vassilakos, P.; Petignat, P. Human papillomavirus self-sampling in Cameroon: Women's uncertainties over the reliability of the method are barriers to acceptance. $J$. Low. Genit. Tract Dis. 2013, 17, 235-241. Available online: https:/ / pubmed.ncbi.nlm.nih.gov/23422643/ (accessed on 5 May 2021). [CrossRef] [PubMed]

11. Kamath Mulki, A.; Withers, M. Human Papilloma Virus self-sampling performance in low- and middle-income countries. BMC Womens Health 2021, 21, 12. [CrossRef]

12. Lazcano-Ponce, E.; Lorincz, A.T.; Cruz-Valdez, A.; Salmerón, J.; Uribe, P.; Velasco-Mondragón, E.; Nevarez, P.H.; Acosta, R.D.; Hernández-Avila, M. Self-collection of vaginal specimens for human papillomavirus testing in cervical cancer prevention (MARCH): A community-based randomised controlled trial. Lancet 2011, 378, 1868-1873. [CrossRef]

13. Camara, H.; Zhang, Y.; Lafferty, L.; Vallely, A.J.; Guy, R.; Kelly-Hanku, A. Self-collection for HPV-based cervical screening: A qualitative evidence meta-synthesis. BMC Public Health 2021, 21, 1503. [CrossRef] 
14. Wakewich, P.; Wood, B.; Davey, C.; Laframboise, A.; Zehbe, I.; on behalf of the ACCSS group. Colonial legacy and the experience of First Nations women in cervical cancer screening: A Canadian multi-community study. Crit. Public Health 2016, 26, 368-380. [CrossRef]

15. Levy, J.; de Preux, M.; Kenfack, B.; Sormani, J.; Catarino, R.; Tincho, E.F.; Frund, C.; Fouogue, J.T.; Vassilakos, P.; Petignat, P. Implementing the 3T-approach for cervical cancer screening in Cameroon: Preliminary results on program performance. Cancer Med. 2020, 9, 7293-7300. [CrossRef] [PubMed]

16. Morgan, K.; Azzani, M.; Khaing, S.L.; Wong, Y.-L.; Su, T.T. Acceptability of Women Self-Sampling versus Clinician-Collected Samples for HPV DNA Testing: A Systematic Review. J. Low. Genit. Tract Dis. 2019, 23, 193-199. [CrossRef] [PubMed]

17. Ministry of Health Cameroon. Plan Stratégique National de Santé Numérique 2020-2024. Available online: https://www.iccpportal.org/system/files/plans/FINAL\%20COPY\%20PSNPLCa\%20FRENCH.pdf (accessed on 9 December 2021).

18. Vassilakos, P.; Tebeu, P.-M.; Halle-Ekane, G.E.; Sando, Z.; Kenfack, B.; Baumann, F.; Petignat, P. Vingt Années de Lutte Contre le Cancer du col Utérin en Afrique Subsaharienne-Collaboration Médicale Entre Genève et Yaoundé. Available online: https:/ / www.revmed.ch/revue-medicale-suisse/2019/revue-medicale-suisse-642/vingt-annees-de-lutte-contre-le-cancerdu-col-uterin-en-afrique-subsaharienne-collaboration-medicale-entre-geneve-et-yaounde (accessed on 5 July 2021).

19. Wong Baker Faces. 2021. Available online: https://wongbakerfaces.org/ (accessed on 19 May 2021).

20. Tasamba, J. Rwanda Scaling Up Fight against Cancer. 2021. Available online: https://www.aa.com.tr/en/africa/rwanda-scalingup-fight-against-cancer/2134720 (accessed on 30 August 2021).

21. Ministry of Health Kenya. Kenya National Cancer Screening Guidelines. 2018. Available online: www.health.go.ke (accessed on 22 August 2021).

22. Ma'som, M.; Bhoo-Pathy, N.; Nasir, N.H.; Bellinson, J.; Subramaniam, S.; Ma, Y.; Yap, S.-H.; Goh, P.-P.; Gravitt, P.; Woo, Y.L. Attitudes and factors affecting acceptability of self-administered cervicovaginal sampling for human papillomavirus (HPV) genotyping as an alternative to Pap testing among multiethnic Malaysian women. BMJ Open 2016, 6, e011022. [CrossRef] [PubMed]

23. Anderson, C.; Breithaupt, L.; Marais, A.D.; Rastas, C.; Richman, A.; Barclay, L.; Brewer, N.T.; Smith, J.S. Acceptability and ease of use of mailed HPV self-collection among infrequently screened women in North Carolina. Sex. Transm. Infect. 2018, 94, 131-137. [CrossRef] [PubMed]

24. Szarewski, A.; Cadman, L.; Ashdown-Barr, L.; Waller, J. Exploring the acceptability of two self-sampling devices for human papillomavirus testing in the cervical screening context: A qualitative study of Muslim women in London. J. Med. Screen. 2009, 16, 193-198. Available online: https:// pubmed.ncbi.nlm.nih.gov/20054094/?dopt=Abstract (accessed on 23 September 2021). [CrossRef]

25. Guan, Y.; Castle, P.; Wang, S.; Li, B.; Feng, C.; Ci, P.; Li, X.; Gravitt, P.; Qiao, Y.-L. A cross-sectional study on the acceptability of self-collection for HPV testing among women in rural China. Sex. Transm. Infect. 2012, 88, 490-494. Available online: https:/ / pubmed.ncbi.nlm.nih.gov/22645391/ (accessed on 23 September 2021). [CrossRef] [PubMed]

26. Pierz, A.J.; Ajeh, R.; Fuhngwa, N.; Nasah, J.; Dzudie, A.; Nkeng, R.; Anastos, K.M.; Castle, P.E.; Adedimeji, A. Acceptability of Self-Sampling for Cervical Cancer Screening Among Women Living With HIV and HIV-Negative Women in Limbé, Cameroon Front. Reprod. Health 2021, 2, 13. [CrossRef]

27. Rosenbaum, A.; Gage, J.C.; Alfaro, K.M.; Ditzian, L.R.; Maza, M.; Scarinci, I.C.; Felix, J.C.; Castle, P.E.; Villalta, S.; Miranda, E.; et al. Acceptability of self-collected versus provider-collected sampling for HPV DNA testing among women in rural El Salvador. Int. J. Gynaecol. Obstet. 2014, 126, 156-160. Available online: https://pubmed.ncbi.nlm.nih.gov/24880188/ (accessed on 5 July 2021). [CrossRef]

28. Bansil, P.; Wittet, S.; Lim, J.L.; Winkler, J.L.; Paul, P.; Jeronimo, J. Acceptability of self-collection sampling for HPV-DNA testing in low-resource settings: A mixed methods approach. BMC Public Health. 2014, 14, 596. Available online: https: / / bmcpublichealth.biomedcentral.com/articles/10.1186/1471-2458-14-596 (accessed on 23 September 2021). [CrossRef]

29. Howard, M.; Lytwyn, A.; Lohfeld, L.; Redwood-Campbell, L.; Fowler, N.; Karwalajtys, T. Barriers to Acceptance of Self-sampling for Human Papillomavirus across Ethnolinguistic Groups of Women. Can. J. Public Health Rev. Can. Santé Publique. 2009, 100, 365-369. [CrossRef]

30. Chen, R.; Wu, L.; Ma, F.; Chen, X.; Zhu, Y. The accuracy and influencing factors for preference of self-sampling in group B streptococcus screening: A cross-sectional study. J. Matern. Neonatal Med. 2021, 1-5. Available online: https://pubmed.ncbi nlm.nih.gov/33618588/ (accessed on 23 September 2021).

31. Khoo, S.; Lim, W.; Rajasuriar, R.; Nasir, N.; Gravitt, P.; Woo, Y. The Acceptability and Preference of Vaginal Self-sampling for Human Papillomavirus (HPV) Testing among a Multi-ethnic Asian Female Population. Cancer Prev. Res. 2021, 14, 105-112. Available online: https:/ / pubmed.ncbi.nlm.nih.gov/32917643/ (accessed on 23 September 2021). [CrossRef] [PubMed]

32. Brandt, T.; Wubneh, S.B.; Handebo, S.; Debalkie, G.; Ayanaw, Y.; Alemu, K.; Jede, F.; Doeberitz, M.V.K.; Bussmann, H. Genital self-sampling for HPV-based cervical cancer screening: A qualitative study of preferences and barriers in rural Ethiopia. BMC Public Health 2019, 19, 1026. [CrossRef] [PubMed]

33. Teng, F.F.; Mitchell, S.M.; Sekikubo, M.; Biryabarema, C.; Byamugisha, J.K.; Steinberg, M.; Money, D.M.; Ogilvie, G.S. Understanding the role of embarrassment in gynaecological screening: A qualitative study from the ASPIRE cervical cancer screening project in Uganda. BMJ Open 2014, 4, e004783. [CrossRef] [PubMed] 
34. Australian Government Department of Health. National Cervical Screening Program-Self-Collection and the Cervical Screening Test. Australian Government Department of Health, 2019. Available online: https:/ / www.health.gov.au/resources/publications/ national-cervical-screening-program-self-collection-and-the-cervical-screening-test (accessed on 15 October 2021).

35. Podolak, I.; Kisia, C.; Omosa-Manyonyi, G.; Cosby, J. Using a multimethod approach to develop implementation strategies for a cervical self-sampling program in Kenya. BMC Health Serv. Res. 2017, 17, 222. [CrossRef]

36. World Health Organization/Uganda. WHO Country Consultation Republic of Uganda. Ministry of Health. The National Cervical Cancer Prevention and Control Strategic Cancer Plan 2020-2025 (September 2020)-Recherche Google. 2020. Available online: https: / / www.afro.who.int/sites/default/files/2021-06/Annual\%20Report\%20WHO\%20Uganda\%202020\%20WEB.pdf (accessed on 30 August 2021).

37. Institut National de la Statistique (INS) and ICF. Enquête Démographique et de Santé 2018. 2020. Available online: https: //www.dhsprogram.com/publications/publication-FR360-DHS-Final-Reports.cfm (accessed on 7 December 2021). 